\title{
Transmisión intrahospitalaria de SARS-CoV-2 en médicos de un servicio de urgencias
}

\section{In-hospital transmission of SARS-CoV-2 in physicians of an emergency department}

Ricardo Rodríguez-Gonzales ${ }^{1, a}$, Khristie Wong-Buckler ${ }^{1, \mathrm{~b}}$, Silvia Pintado-Caballero ${ }^{1, \mathrm{a}}$, Liliana Cieza-Yamunaqué ${ }^{1, c}$, Jimmy Mateo-Pacora ${ }^{1, d}$, José Amado-Tineo,é

\section{Señor editor,}

La infección por SARS-CoV-2 llegó a Perú oficialmente el 6 de marzo del 2020 y 6 meses después ha producido estragos en el sistema de salud. Hasta el 6 de setiembre de 2020 se reporta 689977 pruebas positivas y 29838 fallecidos; mientras que el Colegio Médico reporta 2655 médicos infectados de los cuales 166 han fallecido en todo el país ${ }^{(1)}$.

El trabajador de salud juega un rol muy importante en la atención y control de la enfermedad por coronavirus iniciada 2019 (COVID-19, por sus siglas en inglés). La forma de contagio en este grupo laboral puede ser comunitaria (en domicilio, mercado o transporte) y más probable en el ambiente laboral: por falta de equipos de protección personal (EPP), por uso inadecuado de los mismos o por fallas en la disposición de ambientes y procesos. La carga laboral y la exposición a mayor carga viral influyen en el riesgo de contagio y severidad de la enfermedad ${ }^{(2-4)}$.

En el servicio de urgencias COVID-19 de un hospital general, se realizan turnos asistenciales de 12 horas, divididos en 5 grupos secuenciales (aproximadamente 34 médicos, 40 enfermeros y 50 técnicos de enfermería por grupo), realizándose evaluación diaria de temperatura y mensual de pruebas serológicas para infección por virus SARS-CoV-2; desde inicio de la pandemia cada mes resultaban infectados tres a cuatro médicos que laboraban en dicho servicio. A partir de 28 de junio de 2020, 15 médicos de un mismo grupo presentaron prueba positiva de reacción en cadena de polimerasa con transcriptasa inversa (PCR-RT, por sus siglas en inglés) en hisopado nasofaríngeo (Figura 1),

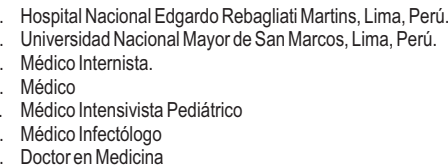

$80 \%$ sintomáticos (fiebre o síntomas respiratorios altos) y dos de ellos ingresaron a unidad de cuidados invasivos con ventilación mecánica invasiva. También 15 enfermeros y 9 técnicos de enfermería del mismo grupo en las mismas fechas tuvieron PCR-RT positiva con síntomas.

Esta tasa de ataque (42,9\%) del total de médico del grupo reportado) es tan alta como lo reportado en un área de la Amazonía peruana ${ }^{(5)}$. La forma de infección en trabajadores de salud es variada, en Italia se reporta que cerca de la mitad de trabajadores de salud infectados por SARS-CoV-2 no tuvieron contacto directo con casos confirmados fuera del ambiente de trabajo y muchos fueron asintomáticos ${ }^{(3)}$. La presentación de tantos casos relacionados, después de varios meses de pandemia por COVID-19 y en un mismo grupo de trabajo hace suponer que no se deba al contacto directo con el pacientes sino a otras formas de contagio como compartir áreas comunes con portadores asintomáticos o sintomáticos no detectados; asociado también inadecuado distanciamiento social o disposición inadecuada de ambientes hospitalarios.

Es importante también considerar las repercusiones físicas, psicológicas y sociales de los trabajadores de salud al contraer la infección. Las principales preocupaciones en este sentido son contagiar a otros (especialmente su familia), el curso que tomará la enfermedad, las secuelas posteriores y su posterior desempeño laboral ${ }^{(4)}$.

Por los motivos expuestos se deben maximizar las medidas preventivas dentro de los hospitales (también en áreas que no tienen relación directa con los pacientes), evaluar la necesidad de realizar PCR-TR en hisopado nasofaríngeo como pruebas de tamizaje y no solamente las pruebas serológicas (para detectar inmunoglobulina $M$ y $G)^{(6)}$. Así como implementar medidas inmediatas de control de brotes ante la presencia de más de dos casos relacionados para minimizar el impacto de esta enfermedad en el 
personal de salud, hecho que revierte negativamente en la atención del paciente.

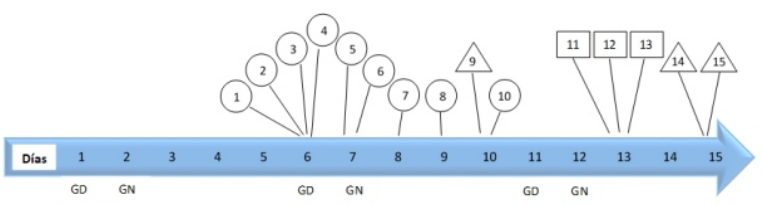

: fiebre, $\Delta$ : síntomas respiratorios altos, $\square$ : asintomático con prueba serológica positiva, GD: guardia diurna, GN: guardia nocturna

Figura 1.

Cronología de detección de infección por SARS-CoV-2 (PCR-RT positivo en hisopado nasofaríngeo) en médicos de un grupo de guardia de un servicio de urgencias.

Conflictos de interés: Los autores niegan conflictos de interés.

Financiamiento: Autofinanciado.

\section{REFERENCIAS BIBLIOGRÁFICAS}

1. Ministerio de Salud. Sala situacional COVID-19 P e r ú. $06-09-2020$. https://covid19.minsa.gob.pe/sala_situacional. asp

2. Tang LH, Tang S, Chen XL, Zhang S, Xiong Y, Chen R, et al. Avoiding health worker infection and containing the coronavirus disease 2019 pandemic: Perspectives from the frontline in Wuhan. Int J Surg. 2020;79:120-124. doi: 10.1016/j.ijsu.2020.05.060. Epub 2020 May 23.

3. Lahner E, Dilaghi E, Prestigiacomo C, Alessio G, Marcellini L, Simmaco M, et al. Prevalence of SarsCov-2 Infection in Health Workers (HWs) and
Diagnostic Test Performance: The Experience of a Teaching Hospital in Central Italy. Int J Environ Res Public Health. 2020;17(12):4417. doi: $10.3390 /$ ijerph17124417.

4. Rivera-Izquierdo $M$, Valero-Ubierna MDC, Martínez-Diz S, Fernández-García MA, MartínRomero DT, Maldonado-Rodríguez F, et al. Clinical Factors, Preventive Behaviours and Temporal Outcomes Associated with COVID-19 Infection in Health Professionals at a Spanish Hospital. International Journal of Environmental Research and Public Health. 2020 Jun;17(12). doi: 10.3390/ijerph17124305.

5. Chafloque-Vásquez RA, Pampa-Espinoza L, CelisSalinas JC. Seroprevalencia de COVID-19 en trabajadores de un hospital de la Amazonía peruana. Acta Med Peru. 2020;37(3):177-9. doi: 10.35663/amp.2020.373.1050

6. Taype-Rondan A, Hurtado-Roca Y, EstradaMartínez M, Timaná-Ruiz R. Recomendaciones clínicas para la evaluación y manejo de riesgo de COVID-19 en personal de salud del Seguro Social del Perú (EsSalud). Acta Medica Peru. $2020 ; 37(1): 84-87$. d o i : 10.35663/amp.2020.371.953.

\section{Correspondencia}

José Percy Amado Tineo

Dirección: Jr Belisario Flores 238 Dpto 301 - Lince. Lima.

Teléfono: 990452547

Correo: jamadot@unmsm.edu.pe

\section{Revisión de pares}

Recibido: 15/09/2020

Aceptado: 20/11/2020 